\title{
Effect of LED Technology on Technical Losses in Public Lighting Circuits. A Case Study
}

\author{
Frank Grau ${ }^{1}$, Janette Cervantes ${ }^{1}$, Luis Vázquez ${ }^{2}$ and José R. Nuñez ${ }^{3, *}$ \\ ${ }^{1}$ Electrical Engineering Department, Universidad de Oriente, Santiago de Cuba, Cuba \\ ${ }^{2}$ Automation Department, Universidad de Oriente, Santiago de Cuba, Cuba \\ ${ }^{3}$ Energy Department, Universidad de la Costa, Barranquilla, Atlántico, Colombia
}

Received 8 December 2020; Accepted 14 April 2021

\begin{abstract}
In this work, an analysis of the quality of electrical energy is carried out, based on the replacement of High-Pressure Sodium Vapor Lamps (HPSV) with Light Emission Diode (LED) lamps in the low voltage networks of public lighting. The study takes into account the advantages and disadvantages of using this technology, among the efforts to reduce electricity consumption and achieve higher rates of electro-energy efficiency. The effect of current harmonics on transformation losses, line losses, and voltage profiles in the circuit is analyzed. Flow runs in the public lighting circuit are obtained from models developed in MATLAB. The models of the loads with harmonic content for the simulation of the lamps were developed from measurements made in the laboratory for these loads. The results obtained due to the replacement of HPSV lamps by LEDs did not show significant differences in terms of harmonic contamination, determining that both technologies present harmonic distortion rates of currents above the standard value. Besides, a significant reduction in the voltage drop and power losses of the lines is achieved, improving the power factor in the distribution network.
\end{abstract}

Keywords: Distribution networks, HPSV, LED, public lighting

\section{Introduction}

Among the latest trends in public lighting, in highly developed countries, LED light-emitting diode technologies and Plasma Induction technologies are developed and applied [1]. Worldwide, public lighting consumes around 218 TWh annually, which represents $8 \%$ of total electricity consumption. In economic terms, this electrical energy translates into 18.7 trillion dollars worldwide, of which $79 \%$ represents the cost of electricity and the remaining percent corresponds to infrastructure, installation, and maintenance [2].

According to data from the Cuban Electric Company in the province of Santiago de Cuba, Cuba, there are approximately 16,000 street lighting fixtures, most of which are made of sodium and mercury vapor. In this city, the public lighting networks show a high level of aging and deterioration, which has led to large investments for their maintenance and the replacement of deteriorated luminaires. Among the investments, the lighting circuits in avenues and main streets have been prioritized, betting on the replacement of lamps by LED technology, much more efficient and with lower energy consumption [3], [4].

Manufacturers of luminaires used in public lighting do not show information on the effect they produce on the quality parameters of the electrical system [5], [6]. In a general sense, public lighting systems must meet a series of technical requirements, such as having a high-power factor, being highly efficient electro-energy systems, having an adequate protection system, and meeting the Electromagnetic

*E-mail address: ricardo10971@gmail.com ISSN: 1791-2377 @ 2021 School of Science, IHU. All rights reserved. doi:10.25103/jestr.142.24
Compatibility (EMC) standards and possess current regulation [7], [8], [9], [10].

The main contribution of this work is aimed at evaluating the technical and economic impact of the replacement of High-Pressure Sodium Vapor Lamps (HPSV) by LED lamps of the lighting circuits, taking into account the effect of current harmonics from of these lamps. Also, it is proposed to evaluate the impact on total technical losses, on lines and transformers, and the voltage profile of urban electrical distribution networks.

The result of this study allows evaluating the quality of the energy that is transmitted and the electro-energy efficiency in the electric energy distribution process. The results are obtained from simulations in MATLAB to analyze public lighting circuits and electrical distribution networks.

The rest of this document is organized as follows. Section 2 describes the main luminaires currently used in public lighting projects. In Section 3, the results obtained in the laboratory are analyzed using an HPSV streetlamp and another LED. Also, simulations of the analyzed model are performed using the SimPowerSystem library of MATLAB, showing the results obtained from the different electrical parameters analyzed. Finally, in Section 4 the conclusions are detailed according to the results obtained.
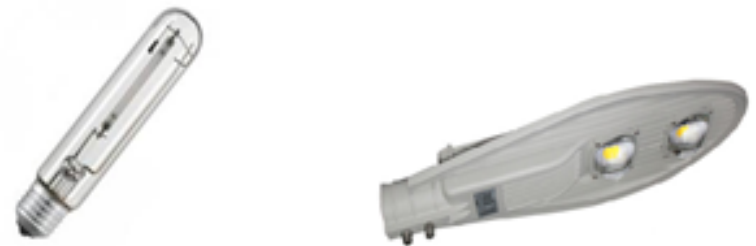

Fig. 1. Types of lamps for public lighting. a) High-Pressure Sodium Vapor Lamp. b) LED lamp 


\section{Materials and methods}

There are not many studies where enough information is found on the effect of LED technology used for public lighting and its importance on the quality of electrical energy in the distribution network [2].

In [11] a model of a high-intensity discharge lamp (HID) driven by an electronic ballast is analyzed in a Matlab Simulink environment, where models of lamps based on dynamic conductance for a 400W HPSV lamp and an electronic ballast are developed. Low-Frequency Square Wave (LFSW) operated at a frequency of $100 \mathrm{~Hz}$. The simulation showed that the maximum deviations of current and constant power are $1.15 \%$ and $-1.341 \%$ respectively for a supply voltage of $180-240 \mathrm{~V}$, which indicates a satisfactory performance of the developed lamp system model.

An LED lamp model in the frequency domain for the calculation of harmonic emissions, together with a simple estimation procedure for the determination of the model parameters from experimental measurements were obtained in [12].

An analysis of the possible impact on the network of three disturbance phenomena: low order harmonics, higher frequency emission, and ignition currents was studied in more than 150 lamps [13]. The data analyzed and the results obtained are organized in a Web database for the exchange of harmonic measurements of electronic equipment between laboratories around the world.

\section{Efficiency $(\mathrm{Im} / \mathrm{W})$}

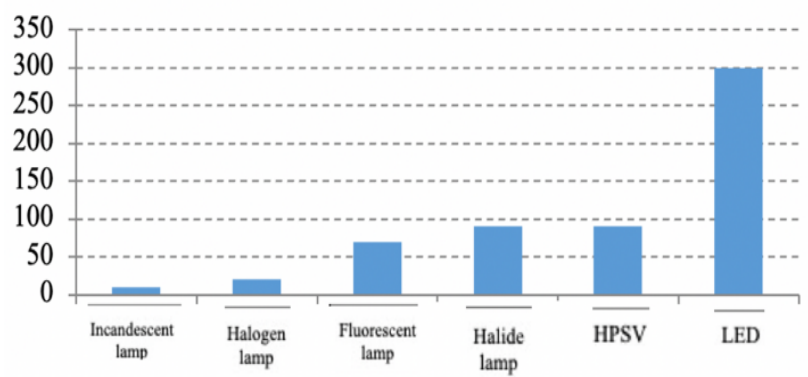

Fig. 2. Efficiency for different light sources [5]

In [14] simulations are carried out showing that the widespread use of lamps with LED technology and compact fluorescent lamps (CFL) will increase the distortion of voltage and current in distribution networks. According to the results, its generalization will not cause sudden changes in the voltage signals, but the current signals could have an unacceptable distortion. Also, the simulations showed an increase in active power losses due to the appearance of high harmonic currents circulating through the elements of the system.

The devices currently used in public lighting projects are high-pressure sodium discharge lamps (HPSV), mercury vapor (VM), and metal halide (MH) discharge lamps. Being in Cuba, the most used are Sodium Vapor and Mercury [3], [4].

The HPSVs shown in Fig. 1a is an illumination source that generates light by creating an electrical discharge through an ionized gas. These lamps achieve considerably better color reproduction than previously used low-pressure sodium bulbs, due to the increase in temperature and the color rendering index that occurs with increasing discharge pressure.

Among the advantages of HPSV lamps, we can highlight that they have a high efficiency ( 80 to $140 \mathrm{~lm} / \mathrm{W})$, more than double that of mercury vapor, a long useful life $(24,000$ hours depending on the manufacturer), and are available in a wide variety of powers, from 35 to $1000 \mathrm{~W}$ [15].

Among their main disadvantages are that they require a ballast with high demands on the start, standard lamps have poor color rendering, and variations in voltage considerably affect their light intensity [16].

Among the efforts to reduce electricity consumption and achieve higher levels of electro-energy efficiency, conventional lighting has been gradually replaced by LED lamps, Figure 1b, not only in public lighting circuits but also in the residential sector, from services and the industrial sector. In [17] a technical and economic comparison of LED lamps with HPSV lamps and metal halide (HM) lamps predominantly used in public lighting in Brazil is made. The study concludes that despite the high costs of implementing public lighting systems that use LED lamps, they present greater efficiency and increase the quality of lighting, which leads to a reduction in lighting energy costs. public and in lamp maintenance, because the useful life of LEDs is declared twice the life of an HPSV and five times greater than the HM. The greatest advantages of LED lamps are in their low consumption of electrical energy coupled with their high luminous efficiency [18]. Fig. 2 shows a comparison regarding the efficiency of the different lamps used in lighting circuits.

In [19] a study is carried out on the spread of light and the highly illuminated areas of the natural environment and the interior spaces of both technologies, where they conclude that, after global warming and global over-lighting, citizens and the lighting industry representatives will be able to identify the existence of light pollution and visual glare as harm rather than a benefit.

A study of the impact of adverse meteorological conditions and environmental pollution on public lighting lamps was analyzed in [20], where the depreciation of the luminaires is evidenced by the level of sealing and the categories of environmental pollution to which these technologies are subjected.

LED lamps in public lighting networks are elements that increase the harmonic pollution of currents, that is, they distort the sinusoidal waveform of the electric current. This distortion can be broken down into different components, known as harmonics; the greater or lesser presence of harmonics is measured with a magnitude known as the Harmonic Distortion Rate (THD). This fact is based on the use of power electronics to supply the energy and control the lamp. From the studies carried out previously [2], [4], [5], for a $120 \mathrm{~W}$ LED lamp the value obtained from the Total Harmonic Distortion of current (THDi) is $18.2 \%$.

For the development of the study of the technical and economic impact on the urban distribution electrical networks, of the replacement of High-Pressure Sodium Vapor Lamps (HPSV) by LED lamps of the lighting circuits, taking into account the effect of harmonics of current coming from these lamps, it is possible to simulate the operation of these networks, using the MATLAB software. For this, the basic topology of radial networks is used, for which it is necessary to connect the nodes, the line sections, the transformers, and the corresponding loads. The simulation allows determining for each section, the value of the electric current, the voltage in the nodes, as well as the losses in the lines. The model of the electrical network is elaborated using the library SimPowerSystem of MATLAB [21]. 


\section{Simulation Pesult}

3.1. Experimental validation of the presence of harmonics in the current signal, in HPSV lamps and LEDs of lighting circuits.

To demonstrate the degree of harmonic distortion in current caused by HPSV lamps and an LED streetlight lamp, a laboratory test was performed. Fig. 3 and 4 show the graphs of voltage and current obtained for each of the cases.

Fig. 3 and 4 show the voltage and current curves for both lamps under study. These curves are obtained from measurements made using an instrumentation system, based on a data acquisition card for the analog-digital conversion of signals using two differential inputs with a scanning frequency of $100 \mathrm{kHz}$ per channel.

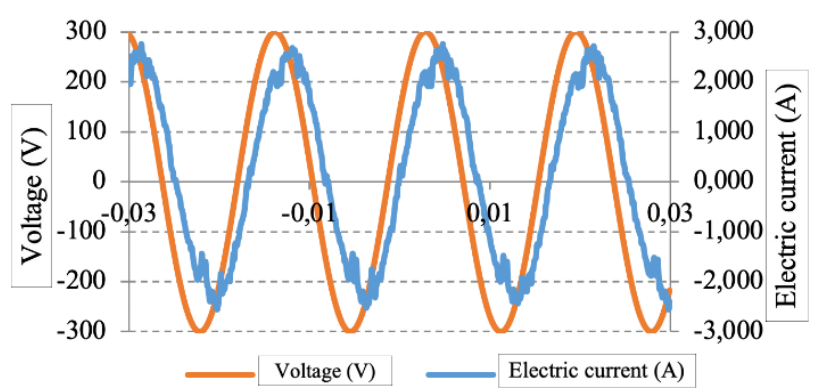

Fig. 3. Voltage and current curves for a 240 W HPSV lamp

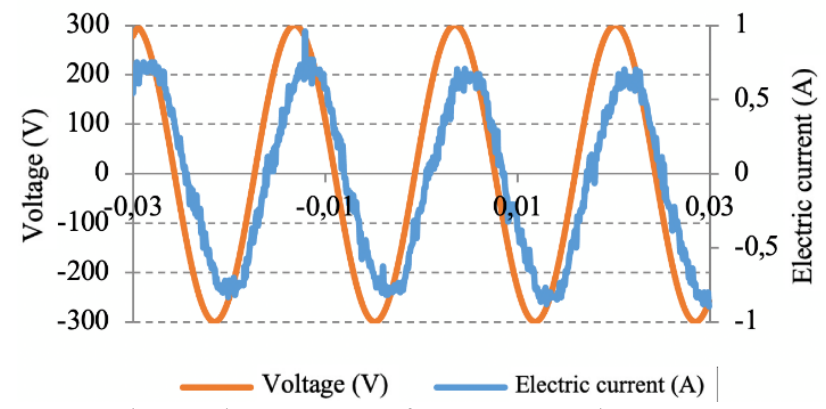

Fig. 4. Voltage and current curves for a 120W LED lamp

The results of the measurements carried out show that the voltage signals for both lamps are practically sinusoidal, on the other hand, a significant level of distortion is observed in the current signals. In the case of the HPSV lamp, the current has a greater phase shift concerning the voltage, which shows that this technology operates with a lower power factor than that of the LED lamp. The digital processing of the signals makes it possible to determine the fundamental parameters of the signals, as well as the harmonic distortion spectrum for the currents. The distortion values are calculated for both cases using an algorithm based on the Discrete Fourier Transform (FFT) from the data of both signals.

Tab. 1 shows the values of the electrical parameters obtained in the laboratory for both lamps.

As can be seen in Tab. 1, similar values of current harmonic distortion have been obtained for both lamps, in both cases being above $10 \%$. The harmonic spectrum as a function of the fundamental is shown in Fig. 5.

Table 1. Results of measurements carried out HPS and LED lamps

\begin{tabular}{llll}
\hline $\begin{array}{l}\text { Electrical } \\
\text { parameters }\end{array}$ & Units & Technologies & LED \\
\hline Electric current & HPSV & 0.54 \\
Voltage & $\mathrm{A}$ & 1.73 & 212.91 \\
Active Power & $\mathrm{V}$ & 213.552 & 108.64 \\
Apparent Power & $\mathrm{W}$ & 309.928 & 114.66 \\
Power factor & $\mathrm{S}$ & 369.75 & 0.948 \\
$\%$ & & 0.838 & 21.7 \\
\hline
\end{tabular}

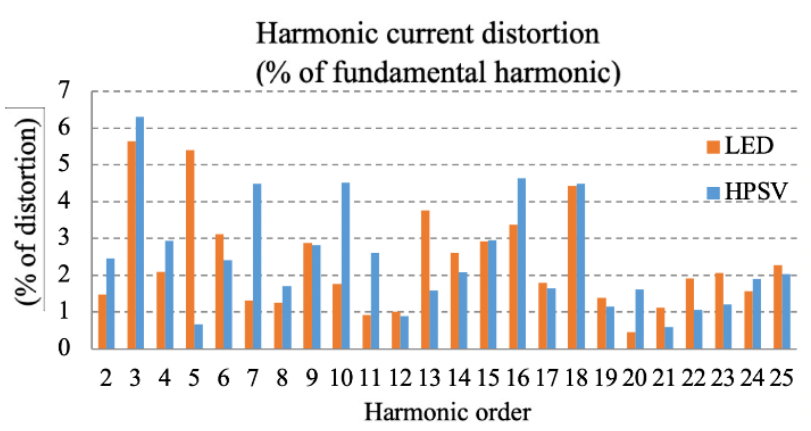

Fig. 5. Harmonic spectrum for the current in both lamps

The amplitude spectrum of the harmonic distortion for both currents reveals that the predominant harmonics are those of order 3, 5, 6, 9, 10 as well as harmonics of higherorder from 13 to 18 . Standard IEC 61000-3-2 [10] sets the limits of the harmonic components for equipment with a current lower than $16 \mathrm{~A}$. The lighting equipment is classified in this standard as Class C. In both cases, the limit value of $3 \%$ is exceeded in the harmonics of order 16 and 18 , and in the case of the LED it is exceeded in the harmonic 13 of the $3 \%$ standard. In the case of the HPSV lamp, for the secondorder harmonic the standard value of $2 \%$ is exceeded. The rest of the harmonics remain below the regulated value.

\subsection{Case study and experimental validation with the use of MATLAB.}

The circuit selected for the study of the technical and economic impact on the urban distribution electrical networks, of the replacement of High-Pressure Sodium Vapor Lamps (HPSV) by LED lamps of the lighting circuits, taking into account the effect of the harmonics of current from these lamps, consists of a single-phase $10 \mathrm{kVA}$ transformer and has a total length of $1071.6 \mathrm{~m}$, with a conductor of uniform diameter $\mathrm{Cu} \varnothing 6$. It has a total of 27 sections with non-uniform distances between them and 28 luminaires. Fig. 6 shows the monolinear circuit diagram.

Tab. 2 lists the length values of the sections of the circuit analyzed, as well as their respective resistance, reactance, and electrical impedance values. 
Table 2. Impedance values per section for the circuit of lighting

\begin{tabular}{|c|c|c|c|c|}
\hline Sections & Length (m) & $\mathbf{R}(\mathbf{\Omega})$ & $\mathbf{X}(\Omega)$ & $Z(\Omega)$ \\
\hline & 5.8 & 0.07328 & 0.00001465 & .07328 \\
\hline : & 4.8 & 0.07168 & 0.00001434 & .07168 \\
\hline i & 6.2 & 0.07392 & 0.00001478 & .07392 \\
\hline t. & 3.6 & 0.08576 & 0.00001715 & .08576 \\
\hline i & 4.7 & 0.07152 & 0.00001430 & .07152 \\
\hline ; & 4.9 & 0.07184 & 0.00001437 & .07184 \\
\hline ' & 3.2 & 0.06912 & 0.00001382 & .06912 \\
\hline ; & 2.9 & 0.06864 & 0.00001373 & .06864 \\
\hline 1 & 5.7 & 0.07312 & 0.00001462 & .07312 \\
\hline 0 & 6.3 & 0.07408 & 0.00001482 & .07408 \\
\hline 1 & 9.9 & 0.07984 & 0.00001597 & .07984 \\
\hline 2 & 5 & 0.08800 & 0.00001760 & .08800 \\
\hline 3 & 7.5 & 0.04400 & 0.00000880 & .04400 \\
\hline 4 & 4.9 & 0.05584 & 0.00001117 & .05584 \\
\hline 5 & 9.9 & 0.07984 & 0.00001597 & .07984 \\
\hline 6 & 1.1 & 0.06576 & 0.00001315 & .06576 \\
\hline 7 & 7.4 & 0.04384 & 0.00000877 & .04384 \\
\hline 8 & 5 & 0.04000 & 0.00000800 & .04000 \\
\hline 9 & 5.5 & 0.04080 & 0.00000816 & .04080 \\
\hline :0 & 9.5 & 0.04720 & 0.00000944 & .04720 \\
\hline$! 1$ & 1.1 & 0.06576 & 0.00001315 & .06576 \\
\hline :2 & 7.4 & 0.04384 & 0.00000877 & .04384 \\
\hline :3 & 9.4 & 0.04704 & 0.00000941 & .04704 \\
\hline 4 & 6.4 & 0.04224 & 0.00000845 & .04224 \\
\hline$: 5$ & .5 & 0.07200 & 0.00001440 & .07200 \\
\hline 6 & 6.9 & 0.05904 & 0.00001181 & .05904 \\
\hline :7 & 7.8 & 0.07648 & 0.00001530 & .07648 \\
\hline
\end{tabular}

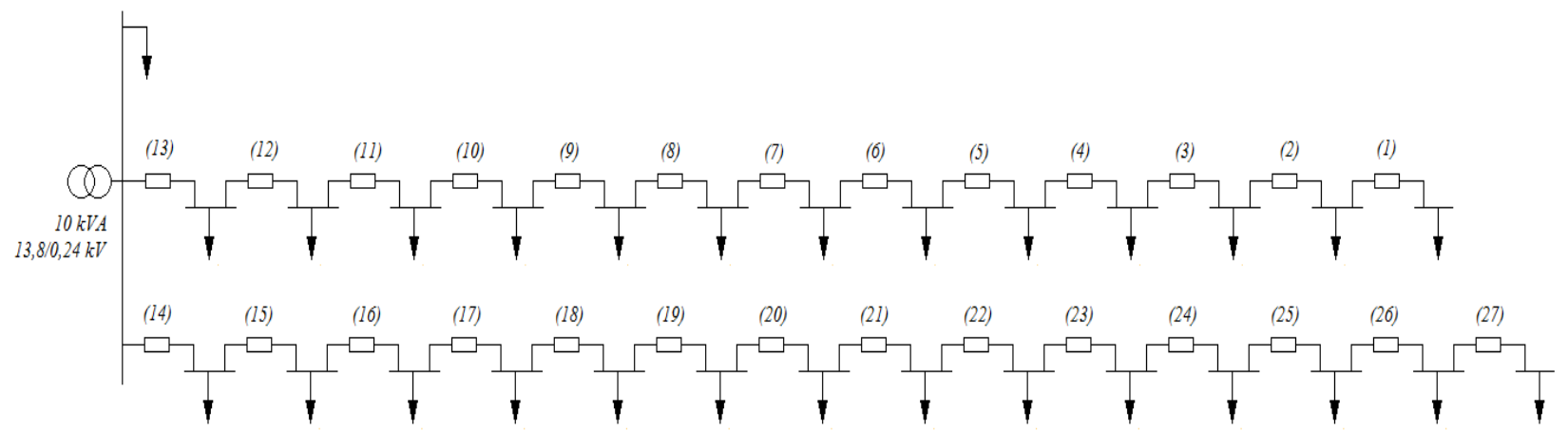

Fig. 6. Unilinear diagram of the public lighting circuit

\subsubsection{Modeling the lamps in MATLAB.}

For the analysis of the effect of non-linear loads in the system, a model was implemented that demands a current from the network with a determined THDi. To achieve this objective, an arrangement of current sources connected in parallel was used, each with a frequency that is a multiple of the fundamental frequency [22]. In this case, the load model was simplified using a programmable current source, as shown in Fig. 7.

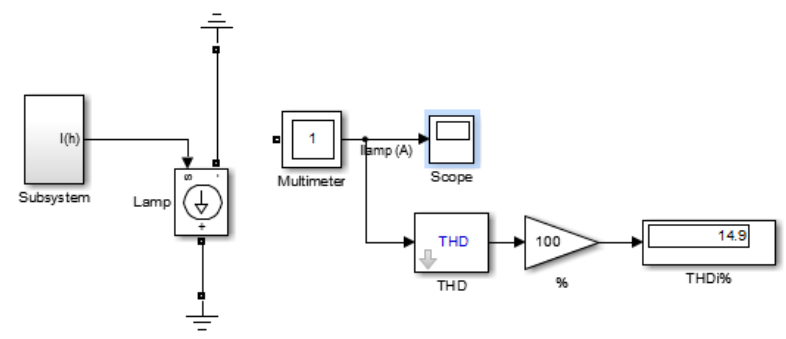

Fig. 7. Model of a non-linear load (lamp) using MATLAB

\subsubsection{Modeling the line in MATLAB}

To carry out an effective study of the circuit, it was necessary to measure the magnitudes of current, voltage, and power in the nodes and the lines. Figure 8 shows the model of a section of line and the load connected to the node of the radial circuit; the line impedances are modeled in the blocks from those taken in Table 2. The loads connected in the nodes correspond to the lamp models implemented in MATLAB, see Fig. 8.

As can be seen in Fig. 8, the simulation of the circuit model makes it possible to determine the voltages at the nodes, the voltage drops in the line sections, the values of the line currents, the current consumed by the load, the losses of power in the lines and the power demanded in each node by the lamp.

In Fig. 9, the result is shown in the representation of a monolinear scheme of the simulated circuit in MATLAB, corresponding to the two-line sections presented in Fig. 8, the loads that are the lamps and the transformer that feeds these loads. 


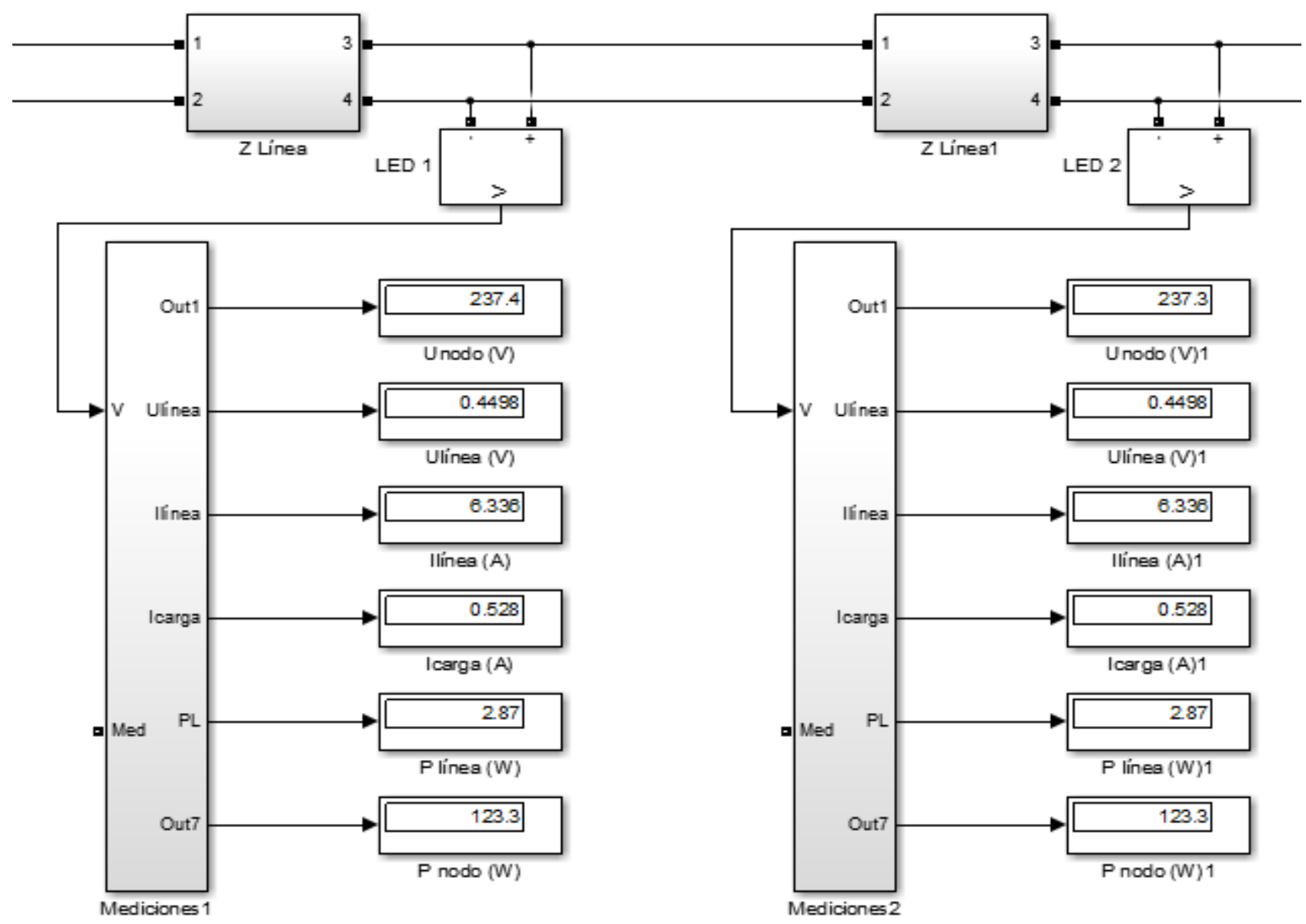

Fig. 8. Example of modeling and simulation of two sections of the lighting circuit

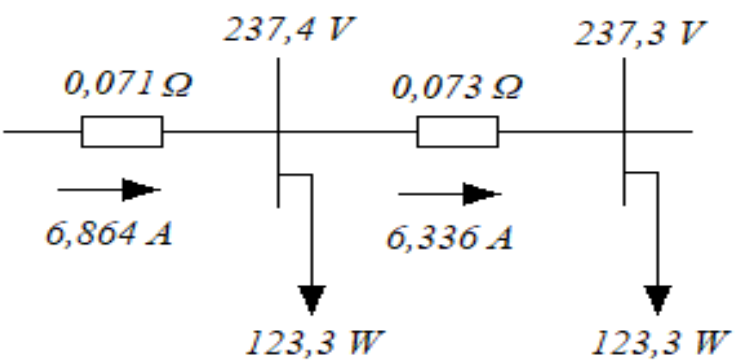

Fig. 9. Example of the model simulation results for a section of the circuit

\subsubsection{Results of the simulation of the operation of the lighting circuit, with its 27 line sections, with loads of HPSV and LED lamps.}

For the simulation of the operation of the public lighting circuit, all the loads and the 27 sections of line were connected to the transformer, as it appears in the monolinear diagram of the circuit, in Fig. 6. The run was carried out and the measurements of the voltage in each one of the nodes, as well as the values of voltage drops in the line sections and power losses in the lines.

With the voltages in each of the nodes of the circuit, it is possible to build a voltage profile of them, as shown in Fig. 10.

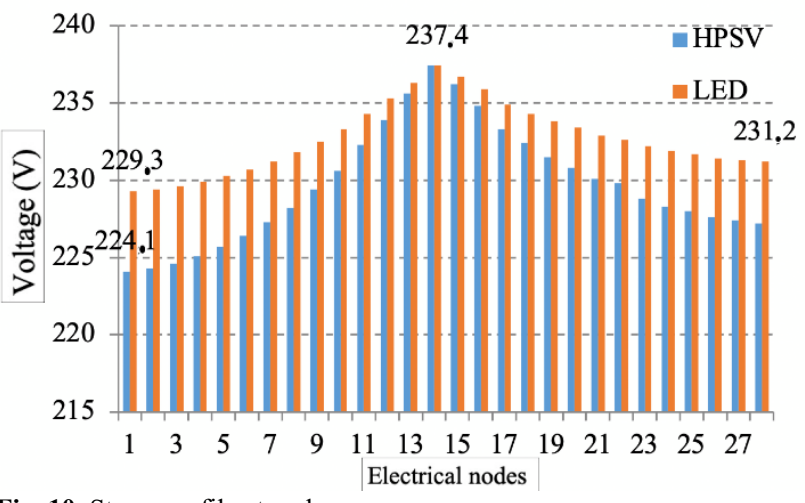

Fig. 10. Stress profile at nodes

The voltage profile shows how the voltage drop in the circuit is considerably reduced from the replacement of luminaires. The highest voltage is $234.7 \mathrm{~V}$, and it is found at node 14 , as it is the node where the transformer is located. The largest voltage drops are at node 1 of the circuit. In this case, the highest voltage drop was obtained for the HPSV analysis, its value being equal to $13.3 \mathrm{~V}$, which represents a $6.6 \%$ deviation of the voltage. This value is reduced to a $4.5 \%$ deviation when the voltage at node 1 increases to $229.3 \mathrm{~V}$ with the replacement of luminaires in the circuit.

In the same way, the power flow reveals a decrease in power losses in the lines by substituting HPSV technology for LEDs in the circuit (see Fig. 11). 


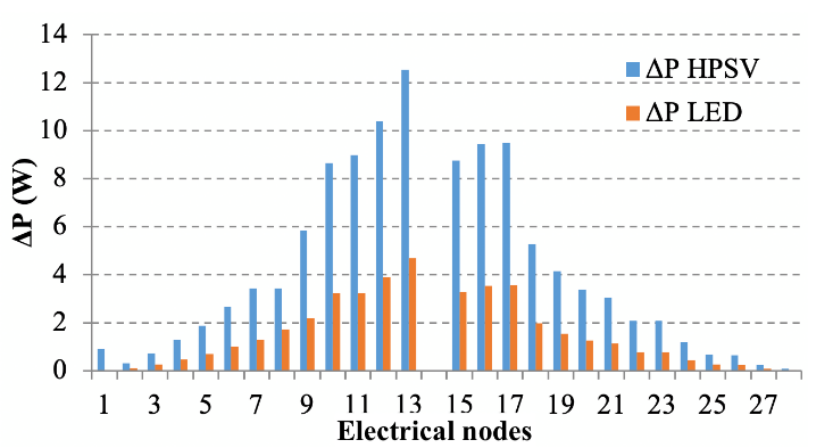

Fig. 11. Profile of power losses $\Delta \mathrm{P}(\mathrm{W})$ for both studies

In the case of the study with HPSV lamps, the power losses in the lines reach a total value of $11 \mathrm{~W}$ when adding the losses in each of the sections. For its part, the study with LED lamps shows total losses in the lines of only $41 \mathrm{~W}$.

3.2.4 Transformer modeling in MATLAB. Result of the simulation of the operation of the transformer with loads of HPSV and LED lamps.

The transformer used in the simulation is single-phase, with a capacity of $10 \mathrm{kVA}$ and has a nominal voltage of $7.9 / 0.24 \mathrm{kV}$. A model of a three-winding linear transformer was used to perform the transformer simulation. The transformer model is based on the Steinmetz equivalent circuit, so it is necessary to know the resistance and reactance values, both of the primary and the secondary, as well as of the magnetization branch. These values are shown in Tab. 3 .

Table 3. Transformer Steinmetz Equivalent Circuit Parameters

\begin{tabular}{c|c}
\hline $\begin{array}{c}\text { Electrical } \\
\text { parameters }\end{array}$ & Values \\
\hline $\mathrm{Sn}(\mathrm{kVA})$ & 10 \\
$\mathrm{f}(\mathrm{Hz})$ & 60 \\
$\mathrm{~V}_{1}(\mathrm{~V})$ & 7967 \\
$\mathrm{~V}_{2}(\mathrm{~V})$ & 0.240 \\
$\mathrm{r}_{1}(\Omega)$ & 61.760 \\
$\mathrm{r}_{2}(\Omega)$ & 0.056 \\
$\mathrm{x}_{1}(\Omega)$ & 76.090 \\
$\mathrm{x}_{2}(\Omega)$ & 0.069 \\
$\mathrm{Rc}(\Omega)$ & 1007509.350 \\
$\mathrm{Xm}(\Omega)$ & 340441.115 \\
\hline
\end{tabular}

The results of the simulation using the model, allow us to obtain the currents and voltages in each one of the windings of the transformer and from these, to calculate the value of the losses with a load of the same using the methodology standard ANSI IEEE C57.110 [10].

The effect of harmonics in transformers is present both in copper losses and in additional losses. In general, the losses in transformers can be included within the transformer's load and no-load losses, according to Eq. 1.

$$
\mathrm{p}_{\mathrm{T}}=\mathrm{p}_{\mathrm{NLL}}+\mathrm{p}_{\mathrm{LL}}
$$

Where $\mathrm{p}_{\mathrm{NLL}}$ is the non-load loss and $\mathrm{p}_{\mathrm{LL}}$ is the load losses.

The vacuum losses are considered to remain constant, as long as high values of harmonic distortion are not obtained in the voltages. On the other hand, the losses under load can be obtained practically from the test of the machine in a short circuit. This can be expressed in the following way, Eq. 2.

$$
\mathrm{p}_{\mathrm{LL}}=\mathrm{p}_{\mathrm{Cu}}+\mathrm{p}_{\mathrm{ED}}+\mathrm{p}_{\mathrm{AD}}
$$

Where $\mathrm{P}_{\mathrm{Cu}}$ are the electrical losses in the windings, $\mathrm{p}_{\mathrm{ED}}$ is the eddy current losses in the windings, and $\mathrm{p}_{\mathrm{AD}}$ is the additional losses in the transformer parts.

In practice, there is no procedure to separate the eddy current losses in the windings from the additional losses. For this reason, the total additional losses $\left(\mathrm{p}_{\mathrm{ADT}}\right)$, made up of the sum of $\mathrm{p}_{\mathrm{AD}}$ with $\mathrm{p}_{\mathrm{ED}}$, are calculated from the difference between the losses under load and the electrical losses according to Eq. 3.

$$
\mathrm{p}_{\mathrm{ADT}}=\mathrm{p}_{\mathrm{ED}}+\mathrm{p}_{\mathrm{AD}}=\mathrm{p}_{\mathrm{LL}}-\mathrm{p}_{\mathrm{Cu}}
$$

Where $\mathrm{p}_{\mathrm{Cu}}$ are the copper losses in the transformer. The electrical losses will be calculated by Eq. 4.

$\mathrm{p}_{\mathrm{Cu}}=\mathrm{I}_{\mathrm{w}}^{2} \mathrm{R}_{\mathrm{w}}$

Where $I_{w}$ is the effective value of the current of each transformer winding, and $\mathrm{R}_{\mathrm{W}}$ is the direct current resistance of each winding.

Fig. 12 shows the voltage and current curves in each of the transformer windings as a result of the simulation.

This model allows measurements of the values of powers, voltages, currents, harmonic distortion of the currents in the windings, THDu, THDi, state of charge of the transformer, and the efficiency. Tab. 4 shows the results of all these variables for each type of lamp.
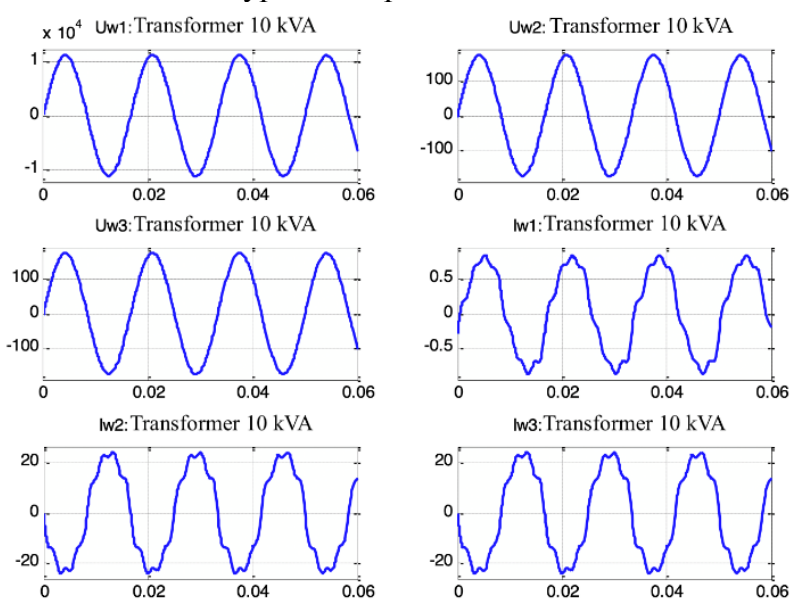

Fig. 12. MATLAB model of the transformer. Case study with LED charging 
Table 4. Results of the operating variables of the transformer understudy

\begin{tabular}{l|c|c}
\hline Measurements Transformer & HPSV & LED \\
\hline P1 (W) & 6891 & 4221 \\
U1 (V) & 7750 & 7750 \\
I1 (A) & 0.889 & 0.545 \\
THDi1 & 0.115 & 0.122 \\
P2 (W) & 6703.5 & 4069.8 \\
U2 (V) & 237.125 & 236.448 \\
I2 (A) & 28.269 & 17.212 \\
THDi2 & 0.116 & 0.124 \\
\% Chargeability & 67 & 40.7 \\
\% Efficiency & 97.3 & 96.4 \\
\hline
\end{tabular}

The spectrum of the harmonic distortion of the current in the secondary of the transformer referred to as the fundamental signal, in percentage values, is shown in Fig. 13.

When carrying out the analysis of the losses with a load of the transformer, starting from the results obtained in the simulations, the value of the losses with load can be determined, broken down into electrical losses ( $\mathrm{p}_{\text {ELEC }}$ ), eddy current losses $\left(\mathrm{p}_{\mathrm{ED}}\right)$ and additional losses $\left(\mathrm{p}_{\mathrm{AD}}\right)$ using expressions 1-4 and calculating the corresponding loss factors.

Following the methodology described in the ANSI IEEE C57.110 [10] standard, the electrical loss factor $\left(F_{\mathrm{ELEC}}\right)$, Eddy effect losses or K Factor, and the additional loss factor $\left(\mathrm{FhA}_{\mathrm{D}}\right)$ are obtained, see Tab. 5.

Transformer load losses and total transformation losses are shown in Tab. 6.

In Fig. 14 the transformation losses for both types of loads are represented.

The total losses due to transformation decrease in correspondence with the decrease in the power demanded and the current that circulates in the network, as can be seen in Fig. 14.

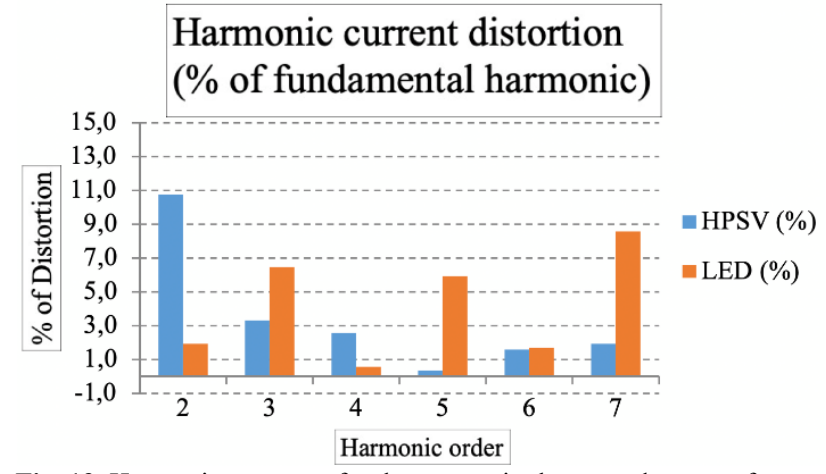

Fig. 13. Harmonic spectrum for the current in the secondary transformer

Together, the transformation losses and the line losses constitute the technical losses in the distribution circuit. From these losses, the energy associated with them can be determined considering a daily use time of 11.5 hours, Tab. 7.

Table 5. Loss factors for the transformer understudy

\begin{tabular}{l|c|c}
\hline Loss Factors & HPSV & LED \\
\hline Fh & 3.15 & 1.180 \\
Factor $\mathrm{K}$ & 0.96 & 0.493 \\
$\mathrm{FhA}_{\mathrm{D}}$ & 0.90 & 0.349 \\
\hline
\end{tabular}

Table 6. Loaded losses of the transformer

\begin{tabular}{l|c|c}
\hline Losses in the transformer & HPSV & LED \\
\hline $\mathrm{p}_{\mathrm{ELEC}}(\mathrm{W})$ & 198.57 & 74.54 \\
$\mathrm{p}_{\mathrm{ED}}(\mathrm{W})$ & 46.24 & 23.72 \\
$\mathrm{p}_{\mathrm{AD}}(\mathrm{W})$ & 73.96 & 28.58 \\
$\mathrm{p}_{\mathrm{LL}}(\mathrm{W})$ & 318.77 & 126.84 \\
Totals $(\mathrm{W})$ & 381.77 & 189.84 \\
\hline
\end{tabular}

On the other hand, the energy-saving due to the replacement of the lamps is determined according to Eq. 5 .

$$
\begin{aligned}
& \Delta \mathrm{E}_{\text {lamps }}=(6.5-3.7) \mathrm{kW} \cdot 11.5 \frac{\mathrm{h}}{\text { day }} \cdot 365 \frac{\text { day }}{\text { year }}= \\
& 11753 \mathrm{kWh} / \text { year }(5)
\end{aligned}
$$

Energy savings from replacing HPSV lamps with LED lamps is calculated using Eq. 6.

$$
\Delta \mathrm{E}_{\text {saving }}=\Delta \mathrm{E}_{\text {lamps }}+\left(\Delta \mathrm{E}_{\mathrm{HPSV}^{-}}-\Delta \mathrm{E}_{\mathrm{LED}}\right)
$$

$$
\Delta \mathrm{E}_{\text {saving }}=11753+(6258.53-2514.27)=15.4 \mathrm{MWh} / \text { year }
$$

The energy saved by replacing lamps in the studied circuit is $15 \mathrm{MWh} /$ year, which represents a saving of energy carriers in the electricity generation process and therefore has a positive impact on the economy of the region and therefore both of the countries.

\section{Conclusions}

With the replacement of HPSV lamps by LEDs, important and considerable decreases in voltage drops in the circuit, transformation losses, and power losses in the lines are 
achieved, also improving the power factor in the distribution network.

The results of the study did not show significant differences in terms of harmonic pollution; however, it was determined that both technologies represent harmonic distortion rates of currents above the norm value.
In the study carried out, the energy-saving represented by the replacement of HPSV lamps by LED lamps in the circuit was verified, because using HPSV lamps the total energy losses amount to $6258 \mathrm{kWh} /$ year, while with the use of LED lamps energy losses are reduced to $2514 \mathrm{kWh} /$ year.

Table 7. Technical losses in the public lighting circuit

\begin{tabular}{|c|c|c|c|c|c|c|}
\hline \multirow[t]{2}{*}{ Technology } & \multicolumn{3}{|c|}{ Transformer } & \multicolumn{2}{|c|}{ Lines } & \multirow{2}{*}{$\begin{array}{c}\Delta E \\
\text { (kWh/year) }\end{array}$} \\
\hline & $\begin{array}{l}\Delta \mathrm{P}_{\mathrm{NLL}} \\
(\mathrm{kW}) \\
0.063 \\
0.063\end{array}$ & $\begin{array}{l}\Delta \mathrm{P}_{\mathrm{LL}} \\
(\mathrm{kW}) \\
0.318 \\
0.126\end{array}$ & $\begin{array}{c}\Delta \mathrm{ET} \\
(\mathrm{kWh} / \text { year}) \\
1599.2 \\
793.3\end{array}$ & $\begin{array}{c}\Delta \mathrm{P} \text { lines } \\
(\mathrm{kW}) \\
0.111 \\
0.041\end{array}$ & $\begin{array}{c}\Delta \mathrm{EL} \\
(\mathrm{kWh} / \text { year) } \\
4659.23 \\
1720.97\end{array}$ & \\
\hline
\end{tabular}

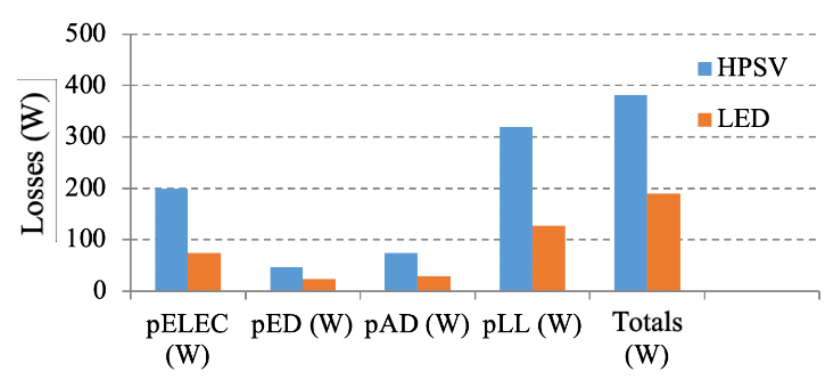

Fig. 14. Loss graph in the transformer in presence of both types of cargo
The energy saved by replacing HPSV lamps with LED lamps in the studied circuit is $15 \mathrm{MWh} /$ year, which represents a saving of energy carriers in the electric power generation process, besides, it has a significant environmental impact related to the decrease of polluting gas emissions into the atmosphere. This result reveals a potential, due to generation, in reducing greenhouse gas emissions of 10 tons/year.

This is an Open Access article distributed under the terms of the Creative Commons Attribution License.

\section{References}

1. M. E. Quiroga, "Análisis de nuevas fuentes en iluminación," Thesis to opt for the Degree of Specialist in Lighting. Engineering Department. Faculty of Engineering. Universidad Nacional de Colombia, Bogotá, (2010).

2. P. Acuña Roncancio, "Impacto del Alumbrado Público con LEDs en la Red de Distribución," Thesis in option to the Magister Degree. Engineering Department. Faculty of Engineering. Universidad Nacional de Colombia, Bogotá, (2011).

3. I. O. Mockey, and E. Manzano, "Trends in the consideration of lighting depreciation of lamps used in road lighting," Revista Ingeniería Energética, vol. XXXVI, no. 1, pp. 21- 32, (2013).

4. I. Salazar, I. O. Mockey, and M. Canal, "Estimation of reduction of $\mathrm{CO}_{2}$ emission by electric power saving project in the Cuba conditions," Revista Ingeniería Energética, vol. XXXI, no. pp. 1$15,(2010)$

5. I. O. Mockey, J. R. Cuerdo, and M. Rodríguez, "Valuation of the luminous depreciation and the energy efficiency of the road lighting systems," Revista Ingeniería Energética, vol. XXXIII, no. 1 pp. 27 34, (2012).

6. NewLux Innovating Light, "LED lighting for public lighting," Catalogue, $2016 . \quad \mathrm{http} / / \mathrm{sw} 3$. in/newlux.com.mx/wpcontent/uploads/2016/11/2016.pdf. (2016).

7. Luminaria Lighting, "LED lighting solutions," https://www.luminalia.es/. Catalogue, (2018).

8. M. S. Rea, "The IESNA Lighting Handbook: Reference \& Application," Editorial Illuminating Engineering Society of North America, 9th edition. New York, United States, p. 1354. ISBN 0879951508. (2020).

9. B. Li, and L. Gu, "The development of LED streetlamp pavement lighting effects testing system," 2014 11th China International Forum on Solid State Lighting (SSLCHINA), Guangzhou, pp. 107110, DOI: 10.1109/SSLCHINA.2014.7127233. (2014).

10. IEC 61000-3-2, International Electrotechnical Commission, Electromagnetic Compatibility (EMC) - Part 3-2: "Limit for harmonic current emissions (equipment input current $<16$ A per phase)", https://webstore.iec.ch/publication/67329, (2020).

11. B. G. Bakshi and B. Roy, "Development \& simulation of dynamic conductance-based high-intensity discharge lamp model driven by low-frequency square-wave electronic ballast," 2016 IEEE 7th
Power India International Conference (PIICON), Bikaner, pp. 1-6, DOI: 10.1109/POWERI.2016.8077164. (2016).

12. J. Molina, J. J. Mesas, N. Mesbahi, and L. Sainz, "LED lamp modeling for harmonic studies in distribution systems," in IET Generation, Transmission \& Distribution, vol. 11, no. 4, pp. 10631071, DOI: 10.1049/iet-gtd.2016.1696. (2017).

13. A. M. Blanco, R. Stiegler, and J. Meyer, "Power Quality Disturbances caused by Modern Lighting Equipment (CFL and LED)". 2013 IEEE Grenoble Conference PowerTech, 2013. art. no. 6652431. ISBN: 978-146735669-5. DOI: 10.1109/PTC.2013.6652431. (2013).

14. A. M. Blanco, and E. E. Parra, "The effects on radial distribution networks caused by replacing incandescent lamps with compact fluorescent lamps and LEDs," Ingeniería e Investigación, Vol. 31, no. 2, pp. 97-101, (2011).

15. ANSI/IEEE Std. C57.110-1998. IEEE, "Recommended practice for establishing transformer capability when supplying non-sinusoidal load currents", IEEE Standards, (1998).

16. B. G. Bakshi, and B. Roy, "A design methodology for acoustic resonance-free, high-frequency, dimmable electronic ballast for high-pressure sodium-vapor lamps", Lighting Research \& Technology, vol. 52, no. 4, pp. 524-539, DOI: $10.1177 / 1477153519875178$. (2020).

17. A. M. E. Pereira, V. A. Teixeira, M. Z. Fortes, A. P. Fragoso, and G. M. Tavares, "Some considerations about LED technology in public lighting," 2015 CHILEAN Conference on Electrical, Electronics Engineering, Information and Communication Technologies (CHILECON), Chile, pp. 561-565, DOI: 10.1109/Chilecon.2015.7400433. (2015).

18. J. Lam and N. A. El-Taweel, "A ZV-ZCS electrolytic capacitorLessAC/DC isolated LED driver with continuous energy regulation," 2016 IEEE Applied Power Electronics Conference and Exposition (APEC), Long Beach, CA, (2016), pp. 830-837. (2016).

19. T. Kyuchukov, "Light Pollution - "Borders" of Lighting Design," 2019 Second Balkan Junior Conference on Lighting (Balkan Light Junior), Plovdiv, Bulgaria, pp. 1-5, DOI: 10.1109/BLJ.2019.8883614. (2019).

20. I. Mockey, and E. Manzano, "The energy impact of luminaire depreciation on urban lighting," Energy for Sustainable 
Development, vol 17, no. 4, pp. 357-362. https://doi.org/10.1016/j.esd.2013.03.006. (2013).

21. W. Gil, O. D, Montoya, and A. Garces, A. "Direct power control of electrical energy storage systems: A passivity-based PI approach," Electric Power Systems Research, vol. 175, 105885. DOI:10.1016/j.epsr. 2019.105885. (2019).
22. C. Liu, H. Bai, H., R. Ma, X. Zhang, F. Gechter, and F. Gao."A Network Analysis Modeling Method of the Power Electronic Converter for Hardware-in-the-loop Application," in IEEE Transactions on Transportation Electrification, vol. 5, no. 3, pp. 650-658, doi:10.1109/TTE.2019.2932959. (2019). 